\title{
CONSELHO ESCOLAR E PRÁTICAS NA GESTÃO DEMOCRÁTICA DA ESCOLA PÚBLICA
}

http://dx.doi.org/10.5902/2318133831679

\author{
Jerffeson Miguel de Oliveira \\ Universidade Estadual do Piauí, Brasil.
}

\begin{abstract}
Resumo
Este artigo é resultado de uma pesquisa desenvolvida com gestores, integrantes de colegiados e docentes de uma escola da rede estadual de ensino do Município de Capitão de Campos/PI. A pesquisa compreende um estudo de caso com abordagem qualitativa, com temática voltada para o conselho escolar e para participação enquanto princípio norteador da gestão democrática. Seu desenvolvimento foi fundamentado nas ideias e concepções de Paro (2016), Lück (2009), Libâneo (2001) e Marques (1990). O objetivo geral da pesquisa consistiu em compreender o papel do conselho escolar nas práticas da gestão democrática. Os objetivos específicos foram refletir acerca de conceitos atribuídos à gestão democrática; analisar na fala dos entrevistados aspectos característicos da gestão democrática e identificar princípios e dimensões desse modelo de gestão. No tocante à problemática buscou responder como a participação no desenvolvimento de atividades, contribui para efetivação da gestão democrática no âmbito escolar. Os procedimentos técnicos para coleta de dados foram pesquisa bibliográfica e entrevista. A análise foi realizada por meio da categorização. Como resultado da pesquisa constatou-se que a participação ativa dos profissionais e da comunidade escolar no desenvolvimento de atividades contribui significativamente para que o modelo da gestão democrática constitua-se efetivo, seja pela influência nas tomadas decisões, seja pela ação direta do conselho escolar. Concluiu-se também, que a efetividade desse modelo de gestão constitui um mecanismo que possibilita desenvolver atividades voltadas para o pleno desenvolvimento do aluno, dos profissionais e da sociedade.

Palavras-chave: gestão democrática; conselho escolar; participação.
\end{abstract}

\section{SCHOOL COUNCIL AND PRACTICES IN THE DEMOCRATIC MANAGEMENT OF THE PUBLIC SCHOOL}

\section{Abstract}

The article is the result of a research developed with managers, collegiate members and teachers of a school of the state school network of the Municipality of Capitão de Campos-PI. The research comprises a case study with a qualitative approach, with themes related to the School Council and for participation as a guiding principle of Democratic Management. Its development was based on the ideas and conceptions of Paro (2016), Lück (2009), Libâneo (2001) and Marques (1990). The general objective of the research is to understand the role of the school council in the practices of democratic management, with the specific objective of reflecting on concepts attributed to democratic management; analyze in the interviewees' speeches characteristic aspects of democratic management and identify principles and dimensions of this management model. Regarding the problem, it seeks to respond, as the participation in the development of activities, contributes to effective democratic management in school? The technical procedures for data collection were bibliographic research and interview, regarding the analysis, was performed through categorization. As a result of the research, it was found that the active participation of 
professionals and the school community in the development of activities contributes significantly to the democratic management model being effective, either by influence in decision making, or by the direct action of the school council It was also concluded that the effectiveness of this management model is a mechanism that allows developing activities aimed at the full development of the student, professionals and society in general.

Key-words: democratic management; school board; participation. 


\section{Introdução}

$\mathrm{O}$ sistema educacional é marcado por constantes mudanças em sua organização, diretrizes, normativas e políticas, que surgem e se modificam de acordo com o momento histórico vivenciado, contingentemente delimitam ou ampliam discussões com foco na educação e sua função social.

A gestão democrática é um dos principais mecanismos de participação da comunidade no espaço escolar, sendo trabalhada com base em princípios que proporcionam e facilitam a intervenção de seus agentes nos vários segmentos da escola. Paro (2016) trata da concepção de que uma educação de qualidade pode ser alcançada por meio de um processo de colaboração, deixando subtendido que, quando escola e comunidade trabalham juntas por um objetivo em comum, se torna mais fácil alcançar os objetivos da escola no tocante a sua função social.

O presente artigo é resultado de um estudo de caso realizado em uma escola da rede estadual de ensino do município de Capitão de Campos. A pesquisa em sua fundamentação aborda ideias e concepções de Paro (2016), Lück (2009), Libâneo (2001) e Marques (1990), contribuindo para melhor compreender a temática e alcançar os objetivos e uma possível resposta para problemática da pesquisa.

A pesquisa teve como objetivo geral compreender o papel do conselho escolar nas práticas da gestão democrática, assim como refletir acerca de conceitos atribuídos à gestão democrática; analisar na fala dos entrevistados aspectos característicos da gestão democrática e identificar princípios e dimensões desse modelo de gestão.

No tocante a problemática, a pesquisa buscou responder a seguinte indagação: como a participação no desenvolvimento de atividades contribui para efetivação da gestão democrática no âmbito escolar?

O tema gestão democrática, além de atual, é dinâmico, abrange de forma específica o papel da comunidade na escola e seu poder deliberativo, sem causar prejuízo à importância de uma ordem hierárquica no espaço interno da escola, por esse e outros fatores, o trabalho se justifica pela necessidade de melhor compreender como acontece esse processo de participação no âmbito escolar.

\section{Gestão democrática da educação: contextualização histórica e bases legais}

A educação é compreendida como universal, uma vez que é de direito de todos. Nos termos da Constituição Federal de 1988, nos art. 205 e 206, inciso I, define-se a igualdade de condições para o acesso e permanência do aluno na escola, que deve se apresentar como espaço onde acontece a transmissão de conhecimentos e valores que devem estar vinculados ao contexto social em que seu público alvo está inserido.

Nesse sentido, as relações estabelecidas entre escola e sociedade, tendem a estreitar-se à medida que se encontram sustentadas por princípios e ideologias que se justificam pelo papel indispensável da educação enquanto processo de construção do ser humano, que como qualquer processo, há a necessidade de se configurar etapas que vão do planejamento de atividades a avaliação dos resultados de suas aplicações práticas.

É nesse contexto, que surgem as primeiras dificuldades em se gerir uma escola, dentre elas o fato de construir um objetivo que seja comum a todos os envolvidos, além de desenvolver atividades que estejam de acordo com a competência de cada profissional ou mesmo gerenciar os recursos, sejam eles pedagógicos ou financeiros, que são 
disponibilizados para realização de cada etapa do processo, e é no surgimento dessas dificuldades que a gestão se apresenta como mecanismo de controle, planejamento e desenvolvimento de estratégias que possibilitem a melhor solução para cada problema que emerge no ambiente escolar.

Para Lück (2009) a gestão escolar se

constitui uma das áreas de atuação profissional na educação destinada a realizar o planejamento, a organização, a liderança, a orientação, a mediação, a coordenação, o monitoramento e a avaliação dos processos necessários à efetividade das ações educacionais orientadas para a promoção da aprendizagem e formação dos alunos. (p. 23)

No entanto, a escola é formada por sujeitos que possuem opiniões e concepções próprias, podendo haver divergências em alguns momentos que se faça necessário decidir algo em favor da escola ou mesmo dos alunos e demais sujeitos que dela fazem parte. Nessa perspectiva a gestão democrática é abordada como base para as tomadas de decisões de caráter coletivo.

Esse modelo de gestão garante assim, que os envolvidos no processo educacional tenham suas opiniões resguardadas e aproveitadas em algum aspecto de um tema ou problemática abordada. Esse modelo de gestão está assegurado por lei, como consta no art. 205, inciso VI da Constituição Federal, onde se apresenta como um dos princípios pela qual o ensino será ministrado, e resguardado novamente pela LDB no art. 3, inciso VIII.

Para Lück (2009) "escola democrática é aquela em que os seus participantes estão coletivamente organizados e compromissados com a promoção de educação de qualidade para todos" (p. 69). O modelo de escola citado pela autora está de acordo com as bases legais que asseguram a gestão democrática no espaço escolar, uma vez que os objetivos dessa gestão são os mesmos resguardados pela LDB e pela Constituição Federal de 1988.

Conforme está presente na Lei de Diretrizes e Bases da Educação Nacional a gestão democrática deve seguir organizada com base em mecanismos de participação:

Os sistemas de ensino definirão as normas de gestão democrática de ensino público na educação básica, de acordo com as suas peculiaridades e conforme os seguintes princípios: I- participação dos profissionais da educação na elaboração do Projeto Político Pedagógico - PPP; IIparticipação das comunidades escolar e local em conselhos escolares ou equivalentes. (Brasil, 2005, p. 12)

O texto exposto evidencia normas as quais estabelecem um espaço que deve considerar, segundo Araújo (2000), os princípios de participação, transparência, pluralidade e autonomia para tomadas de decisões, pois é a partir destes que é possível definir uma gestão como democrática. Nesse sentido é importante estar consciente de que a coletividade se encontra no alicerce dos fundamentos que assegura esse modelo de gestão.

Ao tratamos de participação é de fundamental importância abordar o projeto político pedagógico - PPP - como mecanismo de participação interna e externa: o mesmo se apresenta como uma mediação entre teoria e prática, planejamento e execução. Essa 
mediação deve acontecer de forma que todos os envolvidos no processo de ensino aprendizagem, independente de seu grau hierárquico, possam participar efetivamente para melhor desenvolver as ações que permitirão a escola cumprir seu papel social, bem como oferecer um ensino de qualidade.

Outro mecanismo direto de participação é o conselho escolar: é nele onde devem ser postas em pauta às necessidades básicas da escola, tanto pelos os envolvidos diretamente como indiretamente, que conjuntamente buscarão melhores soluções para os problemas que venham a surgir no decorrer do ano letivo.

\section{Conselho escolar: desafios e possibilidades}

Os conselhos escolares representam a ação da comunidade na escola, o que possibilita que representantes do sistema educacional e da comunidade participem ativamente das tomadas de decisões, buscando, sobretudo, a evolução pessoal e profissional dos alunos. Nesse sentido, os conselhos se apresentam em perspectiva dialógica como o segundo fundamento da gestão democrática, representando a mais clara simbologia da autonomia atribuída à escola, seja ela na dimensão financeira, administrativa ou pedagógica.

No entanto, os conselhos escolares enfrentam dificuldades que limitam sua aplicabilidade, pois mesmo estando asseguradas por lei, muitas instituições de ensino aderem a sua criação apenas em caráter simbólico, ou seja, não saindo do papel. Isso acontece porque em muitos casos estes ficam à mercê da necessidade e em outros do despreparo e falta de conhecimento dos gestores sobre a importância desse e outros órgãos colegiados.

Os conselhos escolares representam uma forma concreta de participação da comunidade na escola, pois os mesmos estabelecem que entre seus membros se tenha representantes da comunidade, no entanto, é preciso compreender que esses conselhos possuem várias instâncias de ação dentro da escola. Para melhor compreender as competências desse sistema, é preciso defini-las de acordo com bases legais, aqui representadas pelo o Programa Nacional de Fortalecimento dos Conselhos Escolares:

Deliberativas: Elaboram normas internas da escola sobre questões referentes ao seu funcionamento nos aspectos pedagógico, administrativo e financeiro. b) Consultivas: quando têm um caráter de assessoramento, analisando as questões encaminhadas pelos diversos segmentos da escola e apresentando sugestões ou soluções, que poderão ou não ser acatadas pelas direções das unidades escolares. c) Fiscais: quando acompanham a execução das ações pedagógicas, administrativas e financeiras, avaliando e garantindo o cumprimento das normas das escolas e a qualidade social do cotidiano escolar. d) Mobilizadoras: quando promovem a participação, de forma integrada, dos segmentos representativos da escola e da comunidade local em diversas atividades (BRASIL, 2004, P. 41).

Nesse sentido, compreende-se que os conselhos escolares precisam ser pensados além do âmbito escolar: por funcionar como mecanismo de participação da comunidade precisa ser efetivado como direito de todos. Tal colocação estabelece competências para os conselhos, de forma que as mesmas possuem caráter descritivo em uma função específica. Esses conselhos podem ser formados por 
representantes dos diversos segmentos da comunidade: estudantes, pais, funcionários, professores, pedagogos, membros da comunidade e diretor da escola. É necessário que as escolas estabeleçam regras democráticas e transparentes na eleição dos segmentos do conselho. "O conselho será a voz e o voto dos diferentes atores da escola, internos e externos, desde os diferentes pontos de vista, deliberando sobre a construção e a gestão de seu projeto político-pedagógico. (Brasil, 2004, p. 37)

O texto exposto esclarece o fato de que os conselhos devem ser democraticamente instituídos na escola e devem assumir a forma deliberativa por meio da qual se utilizam da autonomia como base para as tomadas de decisões, sem que o individualismo seja critério válido para se pensar a realidade da escola, assim, colocando o bem comum como ordem moral e ética para todas as ações.

Desse modo, a autonomia que é concedida aos conselhos condiz com a forma democrática assumida em sua formalidade de inserção e distribuição de atribuições deliberativas que necessitam da atenção reflexiva daqueles que o compõem. Os conselhos escolares são

colegiados compostos por representantes das comunidades escolar e local, que têm como atribuição deliberar sobre questões políticopedagógicas, administrativas, financeiras, no âmbito da escola. Cabe aos Conselhos, também, analisar as ações a empreender e os meios a utilizar para o cumprimento das finalidades da escola. São, enfim, uma instância de discussão, acompanhamento e deliberação, na qual se busca incentivar uma cultura democrática, substituindo a cultura patrimonialista pela cultura participativa e cidadã. (Brasil, 2004, p. 34)

Assim, são infinitas as possibilidades de democratização da escola por meio da inserção da comunidade e da atribuição de poder deliberativo sobre as ações desenvolvidas neste âmbito: a autonomia dos conselhos diz respeito à forma como o mesmo pode agir sem interferência.

Os agentes que compõem o conselho, por adotarem ponto de vista diferente dos que convivem diariamente com os problemas emergentes, representam a possibilidade de um olhar diferenciado, ao tempo em que é visto como uma barreira que limita a formalização dos conselhos, os quais em grande parte das instituições não passam de planos e papeis arquivados.

Nesse sentido, o conselho não pode ser visto como uma sessão desvinculada da escola, ou uma ação externa que possa causar transtornos e caos, pois o mesmo se apresenta como parte da escola, via pela qual a comunidade pode dar sua contribuição para melhor desenvolver o processo e ensino aprendizagem. Libâneo (2003) diz que a organização de atividades que asseguram a relação entre escola e comunidade

implica ações que envolvem a escola e suas relações externas, tais como os níveis superiores de gestão do sistema escolar, os pais, as organizações políticas e comunitárias, as cidades e os equipamentos urbanos. O objetivo dessas atividades é buscar as possibilidades de cooperação e de apoio, oferecidas pelas diferentes instituições, que 
contribuam para o aprimoramento do trabalho da escola, isto é, para as atividades de ensino e de educação dos alunos. Espera-se especialmente, que os pais atuem na gestão escolar mediante canais de participação bem definidos. (p. 348)

Desta forma, a relação escola e comunidade deve ser trabalhada por vários canais de participação, principalmente no desenvolvimento de atividades externas à sala de aula, com foco sobre o conhecimento da rotina diária do aluno, de sua realidade, dificuldades e possibilidades.

\section{Metodologia}

A metodologia utilizada no trabalho foi baseada em Prodanov; Freitas (2013), Marconi; Lakatos (1999) e Yin (2001). Os instrumentos para coleta de dados foram levantamento bibliográfico realizado por meio de pesquisa em fontes confiáveis, como artigos de revistas digitais, periódicos e sites, e aplicação de entrevistas para os gestores, integrante do colegiado e corpo docente do quadro efetivo da instituição de ensino.

$\mathrm{O}$ presente trabalho em sua natureza caracterizou-se como pesquisa pura ou básica, uma vez que a mesma, segundo Prodanov; Freitas (2013) "objetiva gerar conhecimentos novos úteis para o avanço da ciência sem aplicação prática prevista" ( $p$. 51). Nesse sentido buscou-se o entendimento e compreensão acerca do papel do conselho escolar frente o processo de gestão democrática.

Quanto à abordagem, optou-se por uma pesquisa de cunho qualitativo, que segundo Prodanov; Freitas (2013, p. 70): "Considera que há uma relação dinâmica entre o mundo real e o sujeito, isto é, um vínculo indissociável entre o mundo objetivo e a subjetividade do sujeito que não pode ser traduzido em números". Assim, a pesquisa buscou por meio da fala dos sujeitos, identificar características e particularidades que não podem ser computadas, e sim percebidas nas entrelinhas das discussões do tema em questão.

A pesquisa configurou-se como exploratória segundo seus objetivos, uma vez que segundo Prodanov; Freitas (2013, p. 70): "caracteriza-se por possuir planejamento flexível, o que permite o estudo do tema sob diversos ângulos e aspectos. Em geral, envolve levantamento bibliográfico e entrevistas com pessoas que tiveram experiências práticas com o problema pesquisado".

Nesse contexto, compreendeu-se a necessidade de realizar uma pesquisa bibliográfica, onde mesmo sabendo que todo estudo parte de alguma inquietação, a mesma só pode ser estudada a partir do contato com produções já realizadas sobre o tema. Assim, a pesquisa bibliográfica foi utilizada como procedimento técnico, uma vez que, a pesquisa contou com o levantamento de dados a partir de materiais científicos já produzidos e publicados.

A investigação caracterizou-se também como um estudo de caso, pois foi realizada uma análise detalhada de um determinado objeto ou situação específica. Sobre o estudo de caso, Gil (2010), afirma que este: "consiste no estudo profundo e exaustivo de um ou mais objetos, de maneira que permita seu amplo e detalhado conhecimento" (p. 37). 
A coleta de dados foi realizada por meio de entrevista, que segundo Marconi e Lakatos (1999) representa "um encontro entre duas pessoas, a fim de que uma delas obtenha informações a respeito de determinado assunto, mediante uma conversação de natureza profissional" (p. 100). O tipo de entrevista utilizada foi a semiestruturada, ou seja, quando o entrevistador tem mais liberdade para dialogar com o entrevistado.

Este critério permitiu maior aprofundamento e interpretação dos dados obtidos, uma vez que os mesmos não estiveram restritos a perguntas fechadas, ou seja, quando o entrevistado tem mais autonomia para retratar fatos e acontecimentos que ajudam na construção, interpretação e apresentação dos resultados.

O espaço da pesquisa foi o âmbito de uma Escola da Rede Estadual de Ensino do Município de Capitão de Campos. O universo foi constituído pelo núcleo gestor - diretor, coordenador -, professor e integrante do conselho.

Houve no universo da pesquisa uma delimitação que, segundo Marconi e Lakatos (2003), "consiste em explicitar que pessoas ou coisas, fenômenos etc. serão pesquisados, enumerando suas características comuns, como, por exemplo, sexo, faixa etária, organização a que pertencem ou comunidade onde vivem etc." (p. 222). Essa delimitação aconteceu por meio da seleção.

Por fim, o processo de análise foi desenvolvido por meio da categorização e realizado em fases, que Bardin (2009).

\section{Conselho escolar e práticas na gestão democrática: conversando sobre desafios e perspectivas}

A seguir aborda-se os resultados e discussões acerca dos dados que foram registrados por meio de entrevistas. A é a análise das informações contidas no discurso dos entrevistados em consonância com os dados bibliográficos contidos no referencial teórico deste trabalho, que é um estudo de caso realizado em uma escola da rede estadual de ensino do município de Capitão de Campos, estado do Piauí.

Com base na compreensão de que a gestão democrática interiorizada na escola visa, sobretudo, servir de mecanismo para participação da comunidade nas tomadas de decisões, se pensou em questões, que tornassem possível, identificar na fala dos sujeitos, subsídios que comprovassem que essa participação de fato acontece, seja ela por meio da elaboração do projeto político pedagógico, pelo desenvolvimento de projetos, como pela ação direta no conselho escolar ou de órgãos colegiados equivalentes.

Para melhor compreender o conteúdo que será apresentado, optou-se por identificar os sujeitos da seguinte como: diretor (D1), coordenador (C1), membro do conselho (MC1), e professor (P1), as falas serão confrontadas e posteriormente sintetizadas para explicitar as conclusões.

$\mathrm{Na}$ busca por alcançar os objetivos, optou-se inicialmente por indagar os sujeitos a exporem suas concepções sobre gestão democrática:

D1: "Uma gestão onde todos trabalham coletivamente por um mesmo objetivo."

C1: "Aquela que sabe ouvir, que colhe informações e ideias e decide o que é melhor para a escola." 
P1: "É aquela que dar liberdade para todos os agentes que estão envolvidos nela, para poderem discutir um assunto que venha a ser realizado na escola. No caso, se não houver participação, não é uma gestão democrática."

Com exceção do sujeito MC1 percebe-se que todos possuem conceitos ligados ao princípio de participação, seja em relação à comunidade, seja aos próprios sujeitos que constituem o quadro de funcionários da instituição, em relato, fazem a ressalva de que, uma gestão para ser democrática precisa que professores, alunos, pais e todos os envolvidos participem do processo.

Esses argumentos estão sustentados por Lück (2009), quando aborda que "a participação constitui uma forma significativa de promover maior aproximação entre os membros da escola" (p. 85). Assim, compreendemos que não é a atribuição de conceitos, mas sim, a necessidade de mesclar teórica e prática para superar as dificuldades, a fim de tornar esse modelo de gestão cada vez mais presente nos espaços escolares.

Ainda na busca dos objetivos, a categoria seguinte aborda características eminentemente da gestão democrática, pela qual, será possível constatar algumas dificuldades e perceber as possiblidades desse modelo de gestão.

D1: "É onde os envolvidos trabalham em todos os aspectos, havendo a comunicação direta com os funcionários da escola, os alunos e a sociedade."

C1: "Compreendo a gestão democrática como aquela em que há parceria entre todos os envolvidos, incluindo o conselho escolar."

P1: "É uma gestão que acontece quando todos estão diretamente envolvidos nas atividades e projetos da escola."

O discurso dos sujeitos explicita que instaurar um modelo de gestão democrática não é simples, pois, independe apenas do diretor, das normas ou mesmo do empenho de uma ou duas categorias, é preciso que todos de forma geral, estejam coletivamente em harmonia, que compartilhem dos mesmos objetivos e, sobretudo trabalhem em prol de sua concretização.

Conforme o exposto percebe-se que os sujeitos apontam conceitos e características teoricamente positivos da gestão democrática, no entanto, é sabido que não se trata apenas de uma simples conceituação, muitas dificuldades são encontradas na tentativa de efetivar esse modelo nas instituições escolares, como será possível perceber nas categorias seguintes.

Para melhor situar essas dificuldades, serão apresentadas as manifestações que tratam da ação ativa do conselho e da participação do corpo docente no processo de gestão:

MC1: "O Conselho não se envolve muito nas tomadas de decisões, assim, não se caracteriza como totalmente participativo." 
C1: "A falta de comprometimento se apresenta como a maior dificuldade, tanto por parte dos professores como das famílias e dos próprios alunos."

P1: "Não havia participação, por critérios políticos, não havia ações debatidas coletivamente, incluindo a construção do PPP."

As ponderações evidenciam um conflito interno, pois no ambiente perceberam-se características de sujeitos que possuem interesses adversos e que não se situam para promover atividades internas e externas que possibilitem maior interação entre comunidade e escola. Isso se evidencia á medida que o discurso do sujeito MC1 evidencia a baixa participação e poder de decisão do conselho, assim como na manifestação do sujeito $P 1$, quando evidencia o distanciamento entre todos os que compõem a escola, incluindo na elaboração do PPP.

As palavras do autor esclarecem o suficiente sobre o processo da gestão democrática da educação, para que se perceba que não se trata de um processo que deve acontecer apenas de dentro para fora, mas também inversamente, quando cada ação individual de um sujeito pertencente a um grupo ou categoria influencia, motiva ou convida a comunidade a se fazer presente nesse meio.

Neste ponto as questões estão voltadas para discussões que envolvem instâncias de poder deliberativos, também conceituadas como órgãos colegiados. Quanto ao seu poder de decisão é preciso que se tenha uma base legal que assegure a existência das mesmas, além de abordar o projeto político-pedagógico como princípio que assegura a participação dos profissionais da educação em sua elaboração.

Esses argumentos estão resguardados no artigo 14 da LDB, princípio I e II, que estabelecem tanto a participação dos profissionais da educação na elaboração do projeto político-pedagógico, quanto a participação da comunidade escolar e local em conselhos ou equivalentes.

No tocante a essa ponderação, faz-se necessário resgatar uma das abordagens feita aos sujeitos, quando Ihes foi indagado sobre a participação do conselho escolar nas tomadas de decisões, bem como a importância deste órgão colegiado para o desenvolvimento de atividades no espaço interno da escola.

Quando foram indagados sobre o papel do conselho escolar frente às atividades e projetos desenvolvidos, apresentaram as seguintes perspectivas:

D1: "Participar e fiscalizar todas as ações. Sempre havendo a participação de todos os envolvidos, além do conselho."

MC1: "Participar das tomadas de decisões por meio de reuniões, sempre prezando pela coletividade."

Percebe-se nas manifestações dos entrevistados que as atribuições e o papel do conselho frente as atividade e projetos condiz com uma de suas funções deliberativas, como diz respeito a sua função fiscal: Acompanhar a execução das ações pedagógicas, administrativas e financeiras, avaliando e garantindo o cumprimento das normas das escolas e a qualidade social do cotidiano escolar (Brasil, 2004, p. 41). 
Neste ponto a discussão se remete a gestão democrática e sua influência para o desenvolvimento de atividades, onde todos os sujeitos foram indagados a expor suas concepções sobre o assunto.

As atividades e projetos desenvolvem-se em coletividade?

C1: "Sim, há a participação de todos os envolvidos, onde ideias e sugestões são levadas em consideração para realização de projetos e atividades."

F1: "Sim, isso é possível por meio de reuniões e ações em que a visão e a posição dos demais envolvidos são respeitadas e aproveitadas em algum aspecto."

Quais as maiores dificuldades no desenvolvimento das atividades e projetos:

D1: "A falta de motivação, e responsabilidade dos envolvidos."

MC1: "A falta de atuação, e de um sistema de colaboração."

Observa-se que as últimas categorias se confrontam quanto às respostas: se de um lado afirma a existência de trabalho coletivo no desenvolvimento de atividades e projetos, do outro, transparece haver falta de comprometimento dos envolvidos, o que resulta na seguinte questão, como um trabalho é coletivo se não há comprometimento por parte dos envolvidos? Durante a análise das manifestações, se percebe que os sujeitos se contradizem em algumas respostas.

Durante a entrevista, foi possível perceber divisões de grupos com características que pouco contribuem para um trabalho coletivo. Nesse sentido, não basta dizer que a gestão é democrática, é preciso que existam mecanismos para que a mesma se faça presente neste espaço, em todas as dimensões, seja financeira, administrativa ou pedagógica. É preciso que haja a participação, da comunidade, dos alunos, professores, funcionários e demais envolvidos, que juntos busquem as melhores formas de se alcançar um objetivo que esteja comum com o todo.

A percepção acerca do objetivo geral deixa subtendido que o conselho escolar se apresenta na escola como um mecanismo de participação da comunidade, além de assegurar princípios que devem ser resguardados no desenvolvimento de um trabalho coletivo.

No tocante aos objetivos específicos, as entrevistas estimularam os sujeitos a expor com clareza cada aspecto relevante para que fossem alcançados os resultados na análise dos dados, como no primeiro objetivo que busca refletir acerca de conceitos e concepções atribuídas a gestão democrática, da qual o que se percebeu foram definições claras e concisas para este modelo de gestão, os sujeitos expuseram características e finalidades abordando não somente as definições, mais indo além, apontando inúmeras dificuldades para que essas finalidades não sejam de fato alcançadas.

Quanto às características e princípios da gestão democrática percebeu-se que esse modelo de gestão deve pautar suas atividades e projetos nos princípios de base que foram abordados no referencial teórico e nas manifestações dos sujeitos quando trataram 
de autonomia, participação, flexibilidade e outros que são considerados relevantes para desenvolver um trabalho de fato democrático: "A flexibilidade e o envolvimento são princípios de base da gestão democrática” (CM1).

A problemática da pesquisa que buscou identificar como a participação no desenvolvimento de atividades contribui para efetivação da gestão democrática no âmbito escolar, foi respondida com base na análise dos dados, da qual é possível afirmar que a participação contribui para essa efetivação a partir do momento em que é compreendida como princípio norteador desse modelo de gestão, uma vez que quando todos os envolvidos no processo de ensino aprendizagem têm suas ideias e concepções resguardadas, é possível desenvolver práticas transformadoras na vida dos alunos.

\section{Considerações finais}

O percurso da gestão democrática e participativa, de acordo com a pesquisa desenvolvida, se apresenta como processo prático de reflexão, mediação e intervenção no espaço escolar, dando ênfase ao desenvolvimento de atividades realizadas pelos envolvidos.

Conforme a análise dos dados obtidos é notável e preocupante que os gestores enfrentem tantas dificuldades em seu trabalho. Os relatos dos sujeitos apontam para forte presença de fatores que influenciam diretamente na escola, o que pode ser abordado neste trabalho como o eixo que media as discussões acerca dos posicionamentos de cada entrevistado.

A participação é o foco da abordagem da gestão democrática no âmbito educacional, aspecto este característico de um modelo que visa Ao envolvimento de todos que estão ligados ao processo estabelecido para tomadas de decisões, em específico o conselho escolar, tornando-se necessário, refletir sobre a influência que cada sujeito assume diante dos objetivos que neste espaço são almejados.

Diante dos embates que se vivencia no campo educacional, quando cada vez mais a individualidade e as necessidades pessoais estão se constituindo como fatores decisivos, é preciso que haja no fazer profissional dos que estão envolvidos no processo de ensino aprendizagem, seja dentro ou fora da escola, um amplo e extenso processo de reflexão. Nesse sentido, é importante que se conheça inicialmente o discurso desses sujeitos, para que se possa conhecer o processo e só então propor formas de intervir positivamente.

\section{Referências}

ARAÚJO, Adilson César de. Gestão democrática da educação: a posição dos docentes. Brasília: UNB, 200. 220f. Dissertação (mestrado em Educação). Universidade de Brasília.

BRASIL, Lei de Diretrizes e Bases. Lei n. 9.394/96, de 20 de dezembro de 1996.

BRASIL. Plano Nacional de Educação 2014-2024 [recurso eletrônico]: Lei oㅜ 13.005, de 25 de junho de 2014, que aprova o Plano Nacional de Educação (PNE) e dá outras providências. - 2. ed. - Brasília : Câmara dos Deputados, Edições Câmara, 2015. - (Série legislação; n. 193)

BRASIL. Conselhos escolares: democratização da escola e construção da cidadania. Brasília: MEC, 2004.

BRASIL. Constituição da República Federativa do Brasil. Brasília: Senado Federal: Centro Gráfico, 1988. 
FERREIRA, Aurélio Buarque de Holanda, 1910-1989. Novo Aurélio século XXI: o dicionário da língua portuguesa. Rio de Janeiro: Nova Fronteira, 1999.

LIBÂNEO, José. Carlos. Organização e gestão da escola: teoria e prática. Goiânia. Alternativa, 2003.

OLIVEIRA, Dalila. Andrea de (org.). Gestão democrática da educação: desafios contemporâneos. Petrópolis: Vozes, 1997.

LIBÂNEO, José Carlos. O sistema de organização e gestão da escola. In: LIBÂNEO, José Carlos. Organização e gestão da escola: teoria e prática. Goiânia: Alternativa, 2001, p. 2545.

LIBÂNEO, José. Carlos. Organização e gestão da escola: teoria e prática. Goiânia: Alternativa, 2004.

LÜCK, Heloísa. Gestão educacional: uma questão paradigmática. Petrópolis: Vozes, 2006.

LÜCK, Heloísa. Dimensões de gestão escolar e suas competências. Curitiba: Positivo, 2009.

MARCONI, Marina de Andrade; LAKATOS, Eva Maria. Técnicas de pesquisa. São Paulo: Atlas, 1999.

MARQUES, Mário Osório. Projeto pedagógico: a marca da escola. Revista Educação e Contexto. n. 18, 1990, p. 13-30;.

PARO Victor Henrique. Gestão democrática da educação pública. São Paulo: Cortez, 2016.

PRODANOV, Cleber Cristiano, FREITAS, Ernani César. Metodologia do trabalho científico: métodos e técnicas da pesquisa e do trabalho acadêmico. Novo Hamburgo: Feevale, 2013.

YIN, Robert K. Estudo de caso: planejamento e métodos. Porto Alegre: Bookman, 2001.

Jerffeson Miguel de Oliveira é estudante do curso de especialização em Gestão Educacional na Universidade Estadual do Piauí.

Endereço: Rua Presidente Getúlio Vargas, 143 - 64270-000 - Capitão de Campos $\mathrm{PI}$ - Brasil.

E-mail: prof.jerffeson@hotmail.com.

Recebido em 16 de fevereiro de 2018.

Aceito em 20 de abril de 2018. 